\title{
O GÊNERO DO PÚBLICO: CRÍTICAS FEMINISTAS AO LIBERALISMO E SEUS DESDOBRAMENTOS $^{1}$
}

\author{
André Luiz da Silva ${ }^{2}$ \\ Raissa Wihby Ventura ${ }^{3}$ \\ Raquel Kritsch ${ }^{4}$
}

\begin{abstract}
Resumo
0 artigo aborda a distinção, oriunda do pensamento liberal clássico, entre público e privado. Para tanto, expõe-se brevemente alguns dos aspectos principais da teoria feminista, para, em seguida, mostrar a formulação pela teoria política liberal da diferenciação entre público (político) e privado (social) e, mais tarde, entre "público" e pessoal. Tal percurso permite compreender as bases sobre as quais se apóia a teoria feminista para acusar o liberalismo de tratar a justiça como parte exclusiva do domínio público (masculino) e dele excluir a especificidade social das relações de gênero na esfera doméstica. Por fim, discute-se alguns

\footnotetext{
${ }^{1}$ Agradecemos a leitura atenta e as sugestões iniciais feitas por Renata Gonçalves e, sobretudo, por nossa/o construtiva/o parecerista.

${ }^{2}$ Mestrando em Ciências Sociais pela Universidade Estadual de Londrina e em Filosofia pela Universidade Federal de Santa Catarina. End. eletrônico: andre_slv@hotmail.com

${ }^{3}$ Pesquisadora de Iniciação Científica na área de Ciências Sociais pela Universidade Estadual de Londrina e bolsista PIBIC/CNPq. End. eletrônico: raissa_wihby@hotmail.com

${ }^{4}$ Docente junto ao Departamento e ao Programa de Pós-Graduação em Ciências Sociais da Universidade Estadual de Londrina. Publicação vinculada ao Projeto de Pesquisa "Direitos humanos universais e Estados nacionais: fundamentos históricos e problemas teóricos II", financiado pelo CNPq, e desenvolvido junto ao Grupo "Estudos em Teoria Política" (GETEPOLCNPq). End. eletrônico: kritsch@uel.br
} 
aspectos principais do feminismo de Susan Okin e, em especial, seu debate com o liberalismo igualitário de John Rawls, no qual vê possíveis contribuições para a coexistência entre justiça e gênero.

Palavras-chave: Feminismo. Liberalismo. Teoria política. Público/privado.

\title{
THE GENDER OF THE PUBLIC: FEMINIST CRITICISMS OF LIBERALISM AND ITS DERIVATIVES
}

\begin{abstract}
This article addresses the distinction, originating in classical liberal thought, between the public and the private. It lays out briefly some of the principal aspects of feminist theory and then goes on to demonstrate how liberal political theory differentiates between public (political) and private (social) and, later, between "public" and personal. This discussion allows us to understand the basis for feminist theory's accusation that liberalism treats justice exclusively as part of the public (masculine) domain, removing from consideration the social relations of gender in the domestic sphere. Finally, we discuss some of the principle aspects of the feminism of Susan Okin, in particular, her debate with the egalitarian liberalism of John Rawls, in which she sees possible contributions toward the coexistence of justice and gender
\end{abstract}

Keywords: Feminism. Liberalism. Political theory. Public/private.

\section{INTRODUÇÃO}

$\mathrm{D}$ evemos a Simone de Beauvoir a propagação, sobretudo nos círculos intelectuais, da ideia de que as mulheres são dominadas em todos os aspectos de suas vidas e são mantidas em seu lugar inferior pelo "conjunto da civilização". Isto é, as mulheres ocupariam lugar subordinado nos diferentes âmbitos da vida social em virtude de um sem-número de valorações e práticas sociais que marcam a nossa compreensão de masculinidade e feminilidade - uma ideia que pode ser resumida na sua célebre observação de que "on ne naît pas femme, on le devient" ["não se nasce mulher, torna-se mulher"]. Os corpos vêm a ser compreendidos como sexualmente diferenciados por meio de práticas sociais; e é por meio delas que as diferenças entre eles são investidas de significações valorativas. Tornar-se uma mulher consiste num processo histórico e cultural sempre incompleto (BEAUVOIR, 1980, p. 7; 28-9; 500). 
Seguindo o seu rastro, feministas como Kate Millet (1969) e Shulamith Firestone (1970), que despontaram nos anos 1970, iriam argumentar que as formas de dominação detectadas pelas feministas até então eram relativamente superficiais se comparadas com o patriarcado, isto é, com o poder sexual que os homens exercem sobre as mulheres nas várias instituições sociais, políticas, econômicas, mas, sobretudo, na família. Segundo esta perspectiva, pode-se verificar, num amplo leque de sociedades, que a sexualidade masculina constitui a fonte e a justificação do seu poder bem como a característica supostamente natural que thes conferiria o direito de governar as mulheres.

0 patriarcado manifesta-se não só nas relações eróticas entre sexos, mas ainda nas muitas maneiras pelas quais homens e mulheres são socializados (temperamento, papel social, status), em que se supõe que homens devem ser vistos como ativos e potentes, enquanto as mulheres são percebidas como passivas e subordinadas. 0 patriarcado repousa, então, não tanto sobre diferenças biológicas entre homens e mulheres, e sim em interpretações culturais incrustadas em ideias e práticas que conferem a estas diferenças valor e significação (MILLET, 1969, p. 58 e seg.).

Assim, para marcar as diferenças biológicas e socioculturais entre homens e mulheres, feministas como Kate Millet e Ann Oakley, entre outras, sustentariam que é preciso fazer uma distinção - crucial - entre "sexo" e "gênero": sexo diria respeito aos traços biológicos que tornam uma pessoa macho ou fêmea enquanto gênero diria respeito a concepções culturalmente variáveis de masculinidade e feminilidade (OAKLEY, 1985, p. 16).

A distinção de gênero, portanto, como explica Susan Okin, é uma construção social: "refere-se à institucionalização social das diferenças sexuais; é um conceito usado por aqueles que entendem não apenas a desigualdade sexual, mas muitas das diferenciações sexuais como socialmente construídas". (OKIN, 2008, p. 306). Noções como patriarcado, gênero e sexo terminaram por fornecer assim, com o passar do tempo, sustentação conceitual para muitos dos temas anunciados por Beauvoir e deram início a uma série de acirrados debates teóricos que chegaram até nós.

Os estudos feministas concentraram-se, então, em denunciar as gritantes desigualdades de gênero que atingiam a maior parte das mulheres nas mais variadas sociedades. Feministas, em geral, mas especialmente o feminismo de matriz liberal, passaram a lutar pelos direitos legais e políticos das mulheres e pela justeza dos arranjos político-institucionais: o movimento pelo sufrágio universal 
feminino, p. ex., enfatizava a injustiça inerente à negação do direito de voto às mulheres e reivindicava, principalmente, a igualdade de direitos entre homens e mulheres; depois, passou a exigir igualdade de gênero no mercado de trabalho: direitos ao mesmo salário e a iguais oportunidades 5 .

Segundo este raciocínio, a concessão de direitos plenos às mulheres poria fim à desigualdade de gênero existente. 0 problema que se verificou, no entanto, com a conquista de direitos políticos e trabalhistas formalmente iguais pelas mulheres, foi o de que as injustiças e desigualdades sexuais persistiam, apesar da suposta proteção oferecida pelo aparato jurídico estatal às mulheres. Percebeuse que, mesmo onde as leis eram neutras em relação ao gênero, as mulheres permaneciam em desvantagem, como ocorria em boa parte das democracias liberais ocidentais, nas quais não havia mais proibição de atividade política às mulheres, mas elas continuavam sendo minoritárias nas posições de poder político ou de influência.

Tais constatações sugeriam que alcançar a igualdade política plena (e não só formal) poderia exigir algo mais do que leis neutras em relação ao gênero. Como resultado, as feministas procuraram argumentar em favor de uma compreensão do conceito de igualdade que fosse além da mera formalidade das leis neutras ao gênero. Catharine MacKinnon admite que esta abordagem dos direitos - à qual denomina "abordagem diferenciada" da discriminação sexual - ajudou a criar, de fato, acesso e competição neutros quanto ao gênero para benefícios, posições sociais e cargos; mas seu sucesso teria sido limitado, em virtude do fato desta perspectiva centrada na justiça e na igualdade formais ignorar as desigualdades - arbitrárias - embutidas na própria definição destes cargos e das instituições sociais, definição esta que é fundamentalmente masculina. Ou seja, a abordagem da diferenciação entende a igualdade dos sexos em função da capacidade das

\footnotetext{
${ }^{5}$ Esta ênfase na justiça e na igualdade, e a compreensão do Estado como uma arena idealmente neutra dentro da qual as pessoas deveriam ter a possibilidade de perseguir os seus próprios interesses da maneira que quisessem, típicos do pensamento liberal ocidental desde Kant, supõe que a função mais importante do Estado é proteger os indivíduos da interferência de terceiros. Assim, o liberalismo toma como premissas a liberdade e igualdade de todos os seres humanos e justifica 0 Estado enquanto instituição justamente em virtude do fato dele garantir estes dois valores. Ora, ao aceitar esta premissa central, o feminismo liberal assume os direitos das mulheres como indivíduos e, especialmente, o seu direito a um tratamento igual sob a lei, bem como a responsabilidade do Estado em assegurar sua liberdade de se desenvolverem como indivíduos autônomos. Foi este tipo de raciocínio que permitiu ao feminismo liberal, nos seus primórdios, argumentar em favor da igualdade fundamental entre homens e mulheres como seres essencialmente racionais; e demandar um tratamento político e jurídico diferenciado às mulheres, especialmente na esfera pública e no mercado.
} 
mulheres de competir, sob regras consideradas neutras quanto ao gênero, pelos papéis que os homens definiram (MACKINNON, 1987, p. 32-5).

0 problema desta abordagem, no entanto, é justamente esse: igualdade de gênero pode não significar igualdade entre os sexos. É importante saber se o sexo foi levado em conta quando se pensou a instituição ou a/o ocupante do cargo. Pois a igualdade não pode ser alcançada quando se permite que os homens elaborem a maior parte dos papéis e posições sociais relevantes com base numa preferência de gênero, isto é, de acordo com seus interesses (masculinos) ${ }^{6}$. Assim, segundo esta visão, o que determina se a "neutralidade" referente ao sexo engendra ou não igualdade sexual é o fato de o sexo ter sido levado em conta ou não previamente na criação e moldagem dos papéis.

Por isso, é importante perceber que a desigualdade sexual é muito mais um problema de dominação, esclarece Mackinnon (1987, p. 134), de modo que a sua solução não está relacionada somente à ausência de discriminação arbitrária, mas também à presença do poder. Segundo este raciocínio, a subordinação das mulheres resulta da supremacia masculina na definição de papéis e posições socialmente relevantes, sob a qual as diferenças de gênero são tornadas irrelevantes para a distribuição de benefícios, razão pela qual a solução passa por rever padrões de dominação.

0 enfoque da dominação emerge assim a partir da ideia de uma distribuição desigual do poder entre homens e mulheres (ao mesmo tempo que rejeita a superioridade do homem e a subordinação da mulher). MacKinnon (idem) defende que a subordinação não está relacionada com a biologia ou com a forma diferente como os sexos evolveram, mas fundamentalmente com a política. A igualdade requer, portanto, igual poder para criar papéis definidos por mulheres ou para criar papéis que tanto homens como mulheres possam preencher (não requer só a igual oportunidade de buscar papéis definidos por homens). A luta contra a subordinação sexual das mulheres exige, como afirma Elisabeth Gross (1986, p. 193), que se abandone a ideia de interpretar a justiça em termos de igualdade.

Uma das respostas teóricas importantes aos problemas detectados no feminismo liberal viria assim com o chamado "feminismo radical", corrente

\footnotetext{
${ }^{6}$ Ou seja, a incoerência é que os papéis podem ser delineados de maneira que façam com que os homens sejam mais adequados a eles, mesmo em uma competição neutra quanto ao gênero. Neste sentido, a mera neutralidade de gênero não é capaz de impedir a desigualdade entre os sexos, pois as "coisas valiosas" que se busca baseiam-se nos interesses e valores dos homens (MACKINNON, 1987, p. 35-8).
} 
que faria avançar o debate feminista na direção de um questionamento mais profundo das estruturas de dominação patriarcal. De acordo com Elizabeth Gross (idem), já que as mulheres devem ser livres para poderem definir os papéis sociais, seus objetivos deveriam ser descritos, antes, como uma política de autonomia: é preciso abandonar a reivindicação de justiça em termos igualitários (dado que a igualdade é a equivalência de dois termos, o que requer uma medida segundo um padrão prévio). Mais do que de uma "política da igualdade", é preciso, sim, adotar uma "política da autonomia", sustenta Gross. Pois a autonomia implica 0 direito de aceitar ou rejeitar normas e padrões segundo a sua adequação à nossa auto-definição?

Assim, é justamente o feminismo radical, como o nome já sugere, que vai empreender os ataques mais vigorosos contra os objetivos e preocupações da filosofia e da teoria política tradicionais. Enquanto o feminismo liberal, o marxista e o socialista estão inseridos em filosofias políticas que, segundo crêem seus expoentes, podem ser modificadas no sentido de incluir os interesses das mulheres, o feminismo radical é inerentemente crítico em relação à filosofia política como um todo e vê nela uma das muitas maneiras pelas quais o poder masculino é legitimado e perpetuado.

Neste quesito, socialismo, marxismo e liberalismo falham em identificar a causa da opressão das mulheres ao interpretá-la como um caso específico de um problema mais geral. 0 aspecto talvez mais importante da crítica feita pelo feminismo radical está na sua reconstrução da concepção do político. Enquanto o feminismo liberal enfatiza a injustiça das leis existentes, e exige a extensão dos direitos do homem para as mulheres, feministas radicais concebem a injustiça das leis existentes como parte de uma estrutura onipresente da dominação masculina que começa na família e, de lá, expande-se para as instituições políticas. Daí a sua reivindicação de que "o pessoal é político".

\footnotetext{
${ }^{7}$ Nos termos de Gross: "As lutas por igualdade [...] implicam uma aceitação de padrões dados e uma conformidade com suas expectativas e exigências. As lutas por autonomia, por outro lado, implicam o direito de rejeitar tais padrões e de criar padrões novos" (GROSS, 1986, p. 313-4).

${ }^{8}$ Segundo estas feministas, a preocupação tradicional da filosofia e da teoria política com a justiça e a igualdade repousa com frequência sobre a premissa da existência de uma distinção entre vida pública e privada: neste modelo clássico, preocupações acerca da justeza das práticas sociais e das instituições políticas não se estendem, de modo geral, ao mundo privado. Ora, se a filosofia política tem como uma de suas preocupações centrais a justiça das instituições políticas, argumentam as feministas radicais, então é preciso explicar quais instituições contam como políticas e por que. Mais especificamente, é preciso explicar sobre que bases os assuntos domésticos devem ser julgados "privados" e exteriores ao domínio do político.
}

O GÊNERO DO PÚBLICO... 
Segundo este raciocínio, a decisão de diferenciar entre o público e 0 privado, isto é, entre uma área que é e outra que não é uma preocupação legítima do Estado, é em si mesma uma decisão política que acarreta consequências. Assim, a reivindicação feminista de que "o pessoal é político" expressa exatamente esta dimensão política acerca da decisão do que constitui ou não objeto de intervenção do Estado. Na vida privada, argumentam algumas delas, cuidado e compaixão podem ser mais importantes do que justiçâ'; e se a distinção entre mundo privado e mundo político é minada, então parece decorrer daí que cuidado e compaixão devem ser tomados como temas mais proeminentes (enquanto justiça e igualdade devem ser menos valorizados do que usualmente o são na filosofia política).

Deste modo, a ala mais radical do feminismo acaba por subverter a tradição de pensamento político ocidental quando rejeita a existência de um domínio político à parte ou quando insiste que o conceito do político é, em si, "masculino". Trabalhos como os de Genevieve Lloyd (The man of reason, 1984) e Carole Pateman (1989), entre outros, centrados na crítica literária do lugar da mulher na literatura e na filosofia, ofereceram contribuições que marcariam os novos rumos do feminismo radical: em seus escritos, elas procuram mostrar como doutrinas e padrões filosóficos que reivindicam para si um status universal e objetivo refletem interesses particulares, valores e prioridades sintonizados com concepções mais amplas de masculinidade.

Neste sentido, acusam elas, a filosofia contribuiu para construções culturais do gênero que desempenham um papel de relevo na manutenção e legitimação do poder dos homens sobre as mulheres. Esta maneira de argumentar permitiu às feministas radicais dar um passo adiante e questionar a posição privilegiada concedida - por homens, para homens - aos conceitos de justiça e igualdade na filosofia política tradicional ${ }^{10}$.

\footnotetext{
${ }^{9}$ Para este tema, cf. Gilligan (1982) e Ruddick (1995).

${ }^{10}$ Um segundo ponto sensível em suas reflexões voltava-se contra a própria teoria feminista: 0 feminismo deveria rever o hábito, segundo elas equivocado, de fazer reivindicações em nome das "mulheres". Pronunciamentos supostamente universais em nome do gênero, constatam elas, falharam em considerar a diferença entre mulheres de raças diversas, orientações sexuais, nacionalidades e/ou classes distintas. Gênero, como já mostraram outras feministas à exaustão, não é uma categoria natural; por isso, não há nada a ser dito sobre as mulheres enquanto tais. É preciso ser mais sensível às muitas concepções de "feminidade" existentes em diferentes sociedades.
} 


\section{CRÍTICAS FEMINISTAS À DISTINÇÃO ENTRE PÚBLICO E PRIVADO}

Em que termos, então, e com que argumentos, a teoria política feminista, em especial aquela vinculada à abordagem da dominação, enfrenta a distinção liberal entre público e privado?

Em primeiro lugar, retornando ao velho tema da família, um tanto obscurecido pelas preocupações feministas de projetar a mulher na esfera pública e nas instituições políticas. Tal retorno justifica-se à medida que a aplicação da abordagem da dominação à igualdade entre os sexos faz emergir como problemas centrais a distribuição desigual do trabalho doméstico bem como das responsabilidades na família e no local de trabalho. Uma abordagem que se pauta pela ideia da dominação entre gêneros suscita, portanto, questões complicadas quanto às concepções do público e do privado. Como constata Okin,

Em grande parte da corrente predominante da teoria política hoje (em contraste com a teoria feminista), esses conceitos continuam a ser usados como se não fossem problemáticos. Argumentos importantes nos debates contemporâneos dependem da suposição de que questões públicas podem ser facilmente diferenciadas de questões privadas, de que temos uma base sólida para separar o pessoal do político. Algumas vezes explicitamente, mas mais freqüentemente de maneira implícita, perpetuase a ideia de que essas esferas são suficientemente separadas, e suficientemente diferentes, a ponto de o público ou o político poderem ser discutidos de maneira isolada em relação ao privado ou pessoal (OKIN, 2008, p. 305).

Pensadores vinculados às correntes de pensamento hegemônicas na teoria política clássica, tanto de matriz liberal quanto marxista, relutaram em confrontar as relações familiares e julgá-las à luz de padrões de justiça. Pateman (1989, p. 19-22) mostra que os liberais clássicos, p. ex., caracterizaram a familia como uma unidade biologicamente determinada, naturalmente encabeçada por um homem, tal como a entendiam os gregos. Em oposição a este âmbito natural da família eles opunham a justiça, construção da sabedoria humana por excelência, a qual diria respeito a relações determinadas de maneira convencional entre as famílias. Assim, a igualdade natural a que se referiam é aquela do pater familiae como representante das famílias; e sua concepção de contrato social visa a reger as relações entre as famílias.

0 resultado deste raciocínio, como recorda Will Kymlicka (2002, p. 386), é o de que a justiça diz respeito ao domínio "público", no qual homens adultos lidam com outros homens adultos em conformidade com as convenções 
mutuamente acordadas. As relações familiares, por outro lado, são "privadas", governadas pelo instinto ou pela solidariedade naturais. Neste sentido, os teóricos da justiça continuam negligenciando (e até mesmo ignorando) as relações de subordinação presentes dentro da esfera familiar doméstica, ainda suposta, em muitos casos, como um domínio essencialmente natural, comandado em geral pelo homem, cabendo às mulheres executar o serviço doméstico e reprodutivo não remunerado. Assim, ao aceitarem de forma acrítica a divisão entre público e privado e escolherem buscar a igualdade no domínio público, os teóricos da justiça descuidam da questão da unidade familiar doméstica (como também 0 faz boa parte do feminismo liberal ao concentrar-se nos direitos das mulheres na esfera pública e civil).

A consequência mais imediata desse tratamento concedido pela tradição de pensamento político ocidental, até os nossos dias, à distinção entre as esferas pública e privada pode ser percebida, como aponta Seyla Benhabib (2006, p. 216), entre muitas outras feministas, no enclausuramento continuado das mulheres às esferas tipicamente femininas de atividade, como o trabalho doméstico, a reprodução, a gestação e o cuidado dos filhos e dos enfermos, ou seja, no seu confinamento ao domínio privado, o que acarreta a manutenção de sua exclusão do debate público presente no Estado liberal bem como a invisibilidade "pública" de sua opressão e dominação.

Uma realidade que resulta, com frequência, na "dupla jornada" de trabalho feminina, cuja consequência mais visível é a concentração das mulheres em empregos de meio período e baixa remuneração, o que, por sua vez, acarreta sua dependência econômica. E mesmo que esta vulnerabilidade econômica fosse removida, por meio da garantia de uma renda mensal pelo Estado, p. ex., a situação das mulheres ainda continuaria sendo injusta, já que a elas geralmente se coloca uma escolha: aquela que se dá entre a família e a carreira, questão com a qual os homens não se vêem confrontados.

Além disso, lembram várias feministas, deve-se refletir sobre os motivos pelos quais o trabalho doméstico não recebe reconhecimento público. Mesmo quando homens e mulheres compartilham o trabalho não remunerado da casa, o sexismo pode estar presente: ele se manifesta, por exemplo, na avaliação do trabalho doméstico (como inferior, indigno e/ou degradante), e não somente na sua distribuição; e manter-se-á enquanto tal "trabalho feminino" for socialmente desvalorizado. 
Por isso, parte da luta por maior respeito para as mulheres envolve, necessariamente, a revisão e reavaliação de sua contribuição no âmbito doméstico. Pois, segundo estas autoras, a família está no centro da desvalorização cultural e da dependência econômica vinculadas aos papéis tradicionais de gênero. Neste sentido, éde fundamental importância para o feminismo acabar com — ou ainda, rever profundamente - a divisão público/privado, já que, como argumenta Okin (2008, p. 307), "é a permanência dessa dicotomia que torna possível que os teóricos ignorem a natureza política da família, a relevância da justiça na vida pessoal e, consequentemente, uma parte central das desigualdades de gênero." Desse modo, tal instituição, a família, configura-se como um locus importante para a luta por igualdade sexual. Uma luta que deve ir além da discriminação pública: tem de alcançar os padrões do trabalho doméstico e a desvalorização das mulheres na esfera privada.

Ora, se o compromisso liberal com a dicotomia entre público e privado é inquestionável, a afirmação de que o liberalismo tradicional enxerga a familia como o núcleo da vida privada já não é tão uníssona, merecendo algum aprofundamento (embora talvez não se possa dizer o mesmo a respeito da sua relação com a noção de "privacidade" como centro da vida privada, como se discutirá mais adiante). Tais distinções liberais podem ser detectadas em, pelo menos, duas concepções diferentes acerca da diferenciação entre público e privado no pensamento liberal: numa primeira, de matriz lockeana, que separa o político e o social; e numa segunda, que tem origem com os liberais de influência romântica, que distingue entre o "público" e o pessoal.

Explicitar estes dois modos de se conceber a separação entre público e privado imaginados pelo liberalismo pode ser útil não somente para se conhecer melhor os argumentos da teoria política clássica e moderna como também, e principalmente, para ilustrar a posição das feministas neste debate e indicar suas críticas mais contundentes ao liberalismo da justiça.

\section{O PENSAMENTO LIBERAL CLÁSSICO E A DICOTOMIA PÚBLICO/PRIVADO}

A primeira separação entre público e privado na teoria liberal, aquela que distingue o político do social, remonta a John Locke e pode ser ilustrada pela célebre distinção feita por Benjamin Constant entre liberdade dos antigos e dos modernos. 
Segundo ele, a liberdade dos antigos significava a participação ativa no exercício do poder político (e não a fruição da independência pessoal). Já a liberdade dos modernos está ligada à busca da felicidade pelos indivíduos em suas ocupações pessoais e vínculos, o que requer certa "liberação" em relação ao exercício direto do poder político (o que só é possível quando há um conjunto de liberdades e direitos civis constitucionalmente garantidos). Os antigos, frisa ele, sacrificavam sua liberdade privada em prol da vida pública; diferentemente dos modernos, que pensam a política somente como um meio necessário para a proteção de suas vidas privadas (CONSTANT, 1985, p. 10-2).

0 liberalismo está conectado portanto à liberdade moderna, na medida em que separa nitidamente o poder público do Estado das relações privadas da sociedade civil, ao mesmo tempo em que estabelece limites fortes à intervenção do Estado na vida privada. Deste modo, aquela dicotomia formulada pelos gregos, que distinguia entre uma esfera privada da oikos (ou da administração doméstica, identificada com a familia) e outra esfera pública dapolis (âmbito do sociopolítico por excelência, vinculado à ideia de Estado), foi ampliada pelos modernos, que passaram a diferenciar também o social do político, como já mostrou, entre outros, Hannah Arendt, em seu clássico A condição bumana (ARENDT, 1981, p. 37-43).

Esta posição assumida pelo liberalismo clássico - que distingue a sociedade civil do Estado, associando o primeiro termo ao "privado" (sociedade civil é agora o lugar da liberdade liberal) e o segundo ao "público", e conferindo primazia à proteção do âmbito privado em relação a possíveis "ingerências" do Estado - rendeu-lhe muitas críticas: entre outras coisas, é acusado (especialmente por autores comunitaristas) de constituir uma doutrina anti-social, que recusa a natureza inerentemente sociável dos seres humanos, em virtude sobretudo da ênfase que confere à vida privada (que, na visão liberal clássica, inclui a família e as associações livres da sociedade civil bem como o mercado).

Nada mais equivocado do que tal crítica, protesta Kymlicka: embora 0 liberalismo desconfie da política, vê como muito positiva a vida social e a sociedade civil. Como mostra Nancy Rosenblum, a liberdade privada dos liberais pressupõe a sociabilidade natural dos seres humanos. Quando o Estado deixa as pessoas em perfeita independência umas das outras, não as isola e sim as deixa livres para formar e manter "associações e combinações" - aquilo que Rawls chama de "uniões sociais livres". 
Ora, exatamente porque são animais sociais, os indivíduos irão fazer uso de sua liberdade de juntar-se a outros na perseguição de fins comuns (segundo Constant, um ato mais livre do que a unidade coagida das associações políticas). 0 ideal liberal da vida privada, portanto, argumentam eles, não visava proteger o indivíduo da sociedade, e sim libertar a sociedade (mercado, associações, etc.) da interferência política. Por isso, é mais acurado ver o liberalismo como a "glorificação da sociedade", defendem; enquanto o político foi reduzido, nesta concepção liberal, ao símbolo rude da coerção necessária para sustentar a ordem.

Esta primeira distinção entre público e privado operada pelo liberalismo clássico experimentou, como era de se esperar, críticas bastante fortes da teoria feminista, como a de que a maior parte das descrições liberais do âmbito do social/ privado ignoram a contribuição das mulheres na gestação, criação e formação moral daqueles homens adultos e fisicamente capazes que povoam as páginas dos tratados políticos dos pensadores clássicos desde, pelo menos, o século XVII.

Como bem apontou Carole Pateman, o liberalismo, ao conceituar a sociedade civil como um âmbito privado (em oposição ao Estado/público), abstrai dela a vida doméstica atributiva, relegando-a ao esquecimento teórico. A consequência disto é que a separação entre público e privado é apresentada como uma divisão dentro do mundo dos homens, isto é, como uma diferenciação interna ao próprio domínio masculino, que seria expressa não somente pela dicotomia entre público e privado, como também por outras similares, tais como 'sociedade' e 'Estado', 'liberdade' e 'coerção', 'social' e 'político' - todas elas, divisões "dentro do mundo dos homens" (PATEMAN, 1989, p. 121-2 e 128).

Assim, apesar deste movimento dos modernos na direção de uma nova diferenciação (entrepolíticoesocial), a vidadoméstica continuou sendo classificada fora do Estado $e$ da sociedade civil (lugar agora das liberdades e direitos civis dos indivíduos - masculinos - por excelência). Como constata Kymlicka (2002, p. 389), os liberais, preocupados em assegurar que os homens pudessem participar livremente da vida social, "não se preocuparam em garantir que a vida doméstica fosse organizada de acordo com princípios de igualdade e consentimento nem que os arranjos domésticos não impedissem o acesso das mulheres a outras formas de vida social [para além da unidade familiar doméstica]".

E a razão disso é que estes filósofos homens não apenas não tinham qualquer interesse em questionar uma divisão sexual do trabalho da qual se 
beneficiavam, como também pressupunham, teoricamente, como recorda Okin (1979, p. 227-30), que os papéis domésticos fossem fixados de maneira biológica (a inferioridade das mulheres as predestinaria ao cuidado do lar e à maternidade enquanto a superioridade masculina consagraria os homens ao trato dos "assuntos públicos"), de modo que a esfera doméstica e biologizada da família continuou a ser vista como uma limitação da natureza a ser "superada" na vida social e política $^{11}$.

Essa maneira de enxergar o mundo propagada pelo liberalismo tinha consequências óbvias: a esfera doméstica, desde sempre associada às mulheres, permaneceu intacta e "imunizada" ao mundo social e político dos homens e dos grandes feitos. A separação moderna entre social e político, por sua vez, gerou uma nova divisão, agora dentro do âmbito da sociedade civil (associada ao privado, em contraposição ao Estado), a qual passava a abrigar uma nova duplicidade: em seu interior estavam localizados agora tanto o âmbito do mercado e das associações livres entre indivíduos (masculinos) particulares quanto a esfera doméstica da família e suas relações.

Enquanto dos homens esperava-se a atuação nos grandes e pequenos temas sociais do âmbito 'público' da sociedade civil (negócios, jornais, clubes, indústria, sindicatos, etc.), as mulheres eram confinadas à esfera doméstica do trabalho na casa e da (re)produção - biológica e moral - da unidade familiar, isto é, ao âmbito 'privado' (doméstico) da sociedade civil: o lar e suas "prendas".

De fato, pode-se constatar com relativa facilidade, na história do pensamento político de matriz ocidental, que a glorificação daquela ideia de inspiração grega, de que a política é uma forma de vida e uma esfera superior da vida humana, típica dos escritores republicanos modernos e românticos, tinha como contrapartida a aceitação de que a vida doméstica constituía um âmbito marcado por uma natureza particularista, emocional e não universal, cujos vínculos são aqueles do amor e da amizade - todas estas características supostamente femininas (MENDUS e KENNEDY, 1987, p. 10-3; 16).

\footnotetext{
${ }^{11}$ Kymlicka (2002, p. 424, nota 14) levanta uma hipótese interessante a respeito deste assunto: segundo ele, os liberais clássicos sustentavam uma posição similar àquela que tinham os gregos em relação ao âmbito doméstico. "Assim como os antigos viam a esfera doméstica como algo a ser transcendido, a fim de que os homens livres pudessem participar da vida política", escreve, "também os liberais viram a vida doméstica como algo a ser dominado, de modo que ficassem livres para a vida social".
} 
A política constituía, para estes autores, o locus do engenho e do artifício humanos ("cultura"), enquanto a vida doméstica era associada ao domínio heterônomo da necessidade, interesse e desejos particularistas ("natureza", "instintos"). Neste sentido, havia uma clara associação da política àquilo que alegadamente possuía um caráter universal ou comum, e que, por isso, devia ser protegido do e, para tanto, ser separado do domínio das particularidades, sentimentos, emoções e necessidades corporais, de modo que a generalidade do público dependia da exclusão das mulheres.

Neste ponto, especificamente, como mostrou Iris Young (1989, p. 2534), eles se diferenciam dos liberais, para os quais tanto a vida social quanto a doméstica se caracterizam como o reino das necessidades, da heteronomia e das especificidades. Aqui aparece com clareza um ponto de convergência entre feministas e liberais: diferentemente dos gregos, que enxergavam na política a transcendência do reino da naturalidade, e dos hegelianos, que a viam como a superação da particularidade (como telos, portanto), feministas e liberais compreendem o poder público estatal como um instrumento (meio) para a proteção de interesses e necessidades específicas.

No entanto, o fato dos liberais não terem se dedicado a uma maior distinção conceitual entre público, privado e doméstico, chegando mesmo a ignorar este último âmbito, acusam as feministas, já constitui em si razão suficiente para uma crítica da doutrina liberal, sobretudo no que respeita à justiça no interior da família e à desvalorização do trabalho feminino não remunerado, que inclui, entre outras coisas, gestação, parto, educação dos filhos e demais responsabilidades da maternidade. É por isso que 0kin (2008, p. 307) chama a atenção para ambiguidades envolvidas na maior parte das discussões sobre 0 público e o privado.

Uma delas, observa a autora, resulta justamente deste uso inadequado da terminologia para indicar ao menos duas diferenciações conceituais centrais: a dicotomia entre público e privado é utilizada para referir-se à diferenciação tanto 1) entre $o$ Estado e a sociedade (propriedade pública e privada) quanto 2) entre a vida não-doméstica ('pública') e a vida doméstica. Nessas dicotomias, o Estado representa o público, enquanto tanto a família quanto a vida íntima e doméstica são ditas privadas. A diferença entre estes dois usos, aponta Okin, consiste no fato de que o domínio socioeconômico intermediário - aquilo que Hegel denominou de "sociedade civil" - é incluído, na primeira dicotomia, na categoria de "privado", enquanto na segunda é considerado "público" (idem). 
Em sua discussão sobre a dicotomia entre público e privado, Wendy L. Weinstein (apud 0kin, 2008, p. 307) desenvolve uma analogia útil entre publicidade e privacidade e as camadas de uma cebola: assim como numa cebola, em que uma camada está do lado de fora de outra camada, que estará dentro de outra camada, alguma coisa que é pública em relação a uma determinada esfera da vida pode ser considerada privada em relação a uma outra. De acordo com esta afirmação, existe uma multiplicidade de significados (e não somente um significado dual) relacionados às dicotomias Estado/sociedade e não-doméstico/ doméstico.

Em sua análise, Okin opta por operar com a segunda separação, "públicodoméstico", pelo fato de acreditar que é a permanência desta dicotomia que torna possível aos teóricos ignorarem tanto a natureza política da família quanto a relevância da justiça na vida pessoal e, por conseguinte, grande parte das desigualdades de gênero (idem).

Outra ambiguidade localizada por Okin no interior da separação entre público e doméstico é aquela resultante das práticas e teorias patriarcais do passado, que tem sérias consequências práticas, principalmente no que toca ao problema da dominação das mulheres, a saber, a divisão sexual do trabalho, a qual tem fundamental importância para essa dicotomia, até em suas bases teóricas:

Os homens são vistos como, sobretudo, ligados às ocupações da esfera da vida econômica e política e responsáveis por elas, enquanto as mulheres seriam responsáveis pelas ocupações da esfera privada da domesticidade e reprodução. As mulheres têm sido vistas como "naturalmente" inadequadas à esfera pública, dependentes dos homens e subordinadas à família (OKIN, 2008, p. 308).

\section{O LIBERALISMO MODERNO E A DICOTOMIA PÚBLICO/DOMÉSTICO}

Já a segunda distinção entre público e privado no pensamento liberal, a moderna, adotada pelos liberais herdeiros do romantismo, que diferencia 0 pessoal/íntimo do "público" (que aqui inclui Estado e sociedade civil), terminou por substituir, há mais de um século, a primeira dicotomia liberal clássica discutida antes. Esta distinção de origem romântica, nascida como uma crítica conservadora à apologia liberal da sociedade, fundava-se na preocupação romântica com a coerção tanto política quanto social sobre a individualidade, como se lê em Vico, Herder ou Hölderlin. 
Se para os liberais clássicos a sociedade era o domínio básico da liberdade pessoal, para os românticos a individualidade era ameaçada não só pela coerção política (ponto em que concordavam com os liberais) mas sobretudo pela onipresença da pressão social e das expectativas sociais coatoras. Privado, neste raciocínio, é associado a auto-desenvolvimento, criação artística e auto-expressão e significa desvinculação da existência mundana. Como explica Rosenblum (1987, p. 59),

No pensamento liberal clássico, por contraste, "privado" refere-se à sociedade, não ao retiro pessoal; e a sociedade constitui mais um domínio de atividade racional livre do que de licença expressiva. 0 liberalismo protege esta esfera restringindo o exercício do poder governamental e enumerado as liberdades [civis] rivais. 0 romantismo puro e o liberalismo convencional estão separados não apenas por suas noções de vida privada, mas também por suas motivações para designar uma esfera privada privilegiada.

Em sentido estrito, portanto, o que os românticos chamam de domínio privado associa-se à noção moderna de "privacidade" (intimidade): segundo eles, os indivíduos da modernidade precisam de tempo e espaço para si, longe da vida pública (social ou política), a fim de poderem dedicar-se à contemplação, a ideias talvez impopulares, mas capazes de lhes devolver a energia ou ainda de alimentar relações íntimas. Neste sentido, como já notou Arendt (1981, p. 48), a privacidade é o oposto não da esfera política, e sim da esfera social. Ora, os românticos incluíram a vida social na esfera pública exatamente porque os vínculos da sociedade civil, embora não-políticos, permitem a sujeição dos indivíduos ao julgamento e possível censura de terceiros: em assuntos íntimos, como amor e amizade, a vida social e a política podem ser igualmente exigentes.

Esta segunda distinção entre público e privado, embora surgida em oposição ao liberalismo, foi rapidamente assimilada e incorporada pelos liberais modernos, que procuraram integrar a ênfase romântica no perigo das pressões sociais à sua preocupação com a garantia do pluralismo político e social. Desta maneira, o liberalismo moderno passou a se preocupar não apenas com a proteção da esfera 'privada' da vida social, mas também com "esculpir um domínio dentro da esfera privada no qual indivíduos possam ter privacidade. Vida privada, para liberais, significa agora tanto envolvimento ativo nas instituições da sociedade civil [...] quanto retiro pessoal ante aquela vida social ordenada" (KYMLICKA, 2002, p. 395) - ideias que hoje aparecem sob o disfarce jurídico do "direito à privacidade". 
Assim, é como "direito à privacidade" (e não como dicotomia liberal moderna entre 'público' e pessoal) que esta nova maneira de enxergar as relações humanas e o self vai aparecer diante dos tribunais e perante a opinião pública nas sociedades democráticas; e terá defensores liberais de peso, como John Stuart Mill ou Alexis de Tocqueville. Num primeiro momento, tal inovação parecia assegurar às mulheres maiores garantias contra eventuais abusos do poder social e/ou político, e até mesmo no interior da família, sobre a individualidade feminina.

Um julgamento da Suprema Corte dos EUA, ocorrido nos anos 1960, p. ex., determinou que a negação pelo Estado e seus órgãos de acesso a métodos contraceptivos às mulheres casadas constituía violação do direito à privacidade. Uma aparente vitória das mulheres, acreditaram muitos. Ledo engano: não se tardou a perceber que veredito podia ser entendido de maneira diferente. A ideia de um direito à privacidade foi interpretada logo depois no sentido de que toda interferência externa na familia! constituiria violação de privacidade; ou seja, a sentença definiu o direito à privacidade do casal, interpretando-o como vinculado portanto às famílias como unidades (e não a cada um de seus membros).

N. Taub e E. Schneider constatam, a partir de casos como este julgamento da Suprema Corte, que tal medida acabou servindo "para imunizar a família contra reformas destinadas a proteger os interesses das mulheres - por exemplo, a intervenção estatal que protegeria as mulheres contra violência doméstica ou estupro marital [...] ou reconheceria oficialmente o valor do trabalho doméstico" (apud KYMLICKA, 2002, p. 395). Como bem resume MacKinnon (1987, p. 102), o que se verifica é que o direito à privacidade reforça a separação patriarcal entre público e privado, a qual mantém o privado fora do alcance da reparação pública e despolitiza a sujeição das mulheres dentro dele, reforçando assim a tendência de isentar as relações familiares do teste da justiça pública.

Esta dificuldade em assegurar a privacidade da pessoa humana diante da unidade familiar, que pode ser verificada em boa parte das sociedades ocidentais modernas, é resultado, sem dúvida, da forma como o ideal romântico de privacidade adentrou o ordenamento jurídico, fundido com 0 ideal conservador - vinculado à doutrina do pater familiae - da família heterossexual como bastião da sociedade. 0 que se nota em decisões frequentes como esta, que subordinam a privacidade individual à autonomia familiar, é a dificuldade de se "democratizar" a esfera das relações familiares e domésticas num mundo ainda fortemente marcado pelo patriarcado. 0 que pode ser ainda mais difícil quando aqueles que têm interesse 
em manter imune a esfera doméstica adotam a linguagem da privacidade liberal. Como alerta MacKinnon,

provavelmente, não é coincidência que as coisas mesmas que 0 feminismo enxerga como centrais à sujeição das mulheres - o lugar, o corpo; as relações, heterossexuais; as atividades, intercurso e reprodução; e os sentimentos, íntimos - formam o âmago do que é abrangido pela doutrina da privacidade. A partir desta perspectiva, o conceito jurídico de privacidade pode proteger, e protegeu, o lugar do espancamento, do estupro conjugal e do trabalho explorado das mulheres; preservou as instituições centrais pelas quais as mulheres são privadas de identidade, autonomia, controle e auto-definição; [...] Este direito à privacidade é um direito de homens de 'serem deixados em paz' para oprimir as mulheres, uma por vez. Ele incorpora e reflete a definição de feminidade [womanhood] existente na esfera privada. Esta é um exemplo do liberalismo chamado feminista, liberalismo aplicado às mulheres como se nós fossemos pessoas, neutras em relação ao gênero. Ele reforça a divisão entre público e privado, que não é neutra em relação ao gênero. Ele tanto constitui uma divisão ideológica que está disseminada na experiência compartilhada das mulheres quanto mistifica a unidade [existente] entre as esferas de violação das mulheres. É uma divisão bastante material que mantém o privado fora do alcance da reparação pública e despolitiza a sujeição das mulheres dentro dele (MACKINNON, 1987, p. 101-2).

Isto significaria então que as feministas rejeitam a defesa liberal de um espaço de privacidade na vida de seres humanos? Todas as esferas da vida e das relações humanas, inclusive as do amor e amizade, segundo as teorias feministas, deveriam estar abertas ao controle social e político no Estado de direito?

Obviamente, sobre questões polêmicas como estasnão háconsenso. Algumas feministas mais radicais, em sua luta para derrubar as fronteiras patriarcais que separam o público do privado - e, com isso, excluem as mulheres da vida pública, relegando-as ao esquecimento e à desvalorização da domesticidade -, insistem no slogan de que "o pessoal é político", razão pela qual não deveria haver nenhuma esfera da vida humana imune ao controle socioestatal. Mas esta posição tem se tornado cada vez mais minoritária entre a/os teórica/os do feminismo.

Em primeiro lugar, quando se estuda de maneira mais detida a história do pensamento político no mundo ocidental, pode-se notar que a identificação da privacidade com a unidade familiar doméstica não expressa adequadamente os fundamentos da doutrina liberal. Estudos políticos clássicos, e também recentes, inclusive de autoras dedicadas ao feminismo, mostram que, desde pelo menos o 
século XVII, tanto os direitos políticos quanto aqueles relacionados à concepção liberal moderna de privacidade e privado têm sido definidos e defendidos como direitos dos indivíduos (e não da família ou do casal); é fato, contudo, também, que tais indivíduos foram frequentemente descritos como homens, adultos, chefes de família, brancos, capazes, heterossexuais, católicos ou protestantes, como se pode ler fartamente nos tratados clássicos de filosofia política.

Deste modo, os direitos destes indivíduos (masculinos) de disporem de uma esfera em que pudessem usufruir de liberdade em relação ao domínio do Estado, da igreja, ou da vigilância de terceiros, representavam, ao mesmo tempo, direitos que conferiam a possibilidade de não sofrerem qualquer tipo de interferência no controle que pudessem exercer sobre os demais membros - subordinados que compõem a esfera da vida privada, leia-se, a unidade doméstica da família. Assim, não encontramos nestas teorias qualquer suposição de que os membros considerados subordinados (mulheres, filhos, "agregados", etc.) pudessem ter seus próprios direitos à privacidade: a unidade familiar simplesmente não é objeto das considerações acerca da justiça pública no raciocínio destes pensadores.

Alison Jaggar (1983, p. 145) chama a atenção para a multiplicidade de posições entre a/os teórica/os feministas no que concerne à divisão entre público e privado: segundo ela, tanto as feministas radicais como as socialistas tendem, por razões distintas, a defender a abolição da separação entre público e privado, enquanto feministas ditas "liberais" tendem a sustentar uma definição mais restrita da vida privada e da privacidade. Pateman (1989, p. 134) é um exemplo de feminista que busca distanciar-se da interpretação de que "o pessoal é político", embora afirme que a crítica feminista precisa desenvolver uma alternativa à concepção liberal que abranja a relação entre a vida pública e a doméstica.

Okin (2008, p. 313-4), por sua vez, discorda de Jaggar, no sentido de que tais distinções entre feminismo liberal, radical ou socialista possam ser feitas tão claramente. Para ela, muitas feministas que partem de diversas posições políticas não negam, de maneira alguma, nem a utilidade do conceito de privacidade e nem o valor da privacidade na vida humana, além de aceitarem que existem distinções sensatas a serem feitas quanto às esferas pública e doméstica. Como recorda Anita Allen (1988, p. 33), inúmeras reivindicações relevantes para as feministas, dos direitos reprodutivos à proteção contra o assédio sexual ou estupro, estão baseadas no direito das mulheres a vários tipos de privacidade.

Okin (2008, p. 314) acrescenta que, somente se um alto grau de igualdade for mantido na esfera doméstica da vida familiar, esta pode ser entendida 
como um âmbito privado consistente com o direito à privacidade e à segurança socioeconômica de mulheres e crianças. Com o avanço do debate entre as feministas, a afirmação de que o "pessoal é político" vem sendo reformulada: muitas teóricas questionam, hoje, "o quanto o pessoal é político?" Esta é uma forte tensão tanto para o feminismo liberal como para o socialista. Okin (idem) explica que este questionamento quer dizer

[...] primeiramente, que o que acontece na vida pessoal, particularmente nas relações entre os sexos, não é imune em relação à dinâmica de poder, que tem tipicamente sido vista como a face distintiva do político. [...] nem o domínio da vida doméstica, pessoal, nem aquele da vida não-doméstica, econômica e política, podem ser interpretados isolados um do outro.

A autora procura sustentar que as desigualdades entre homens e mulheres no mundo do trabalho e da política estão inextricavelmente relacionadas às desigualdades que ocorrem no interior da unidade familiar, criando um ciclo causal de dupla direção. Por terem muito clara a ideia de que a organização social contemporânea é atravessada pela percepção predominante da vida social como separada em duas esferas distintas, as feministas têm desenvolvido argumentos convincentes mostrando que boa parte desse pensamento dual leva a equívocos; e, ainda, que esse opera no sentido de reificar, e com isso legitimar, a estrutura hierarquizada de gênero da sociedade bem como de proteger uma parte significativa da vida humana do exame ao qual o político é submetido a todo o momento (OKIN, 2008, p. 315).

Como se pode notar, algumas destas teóricas do feminismo afirmam que a separação liberal entre público e doméstico é fundamentalmente ideológica, pois apresenta a sociedade a partir de uma perspectiva masculina tradicional (patriarcal), baseada em pressupostos diversos sobre as distintas naturezas e diferentes papéis considerados "naturais" de homens e mulheres; e que, concebida desta maneira, não pode servir como um conceito central a uma teoria política que procura incluir a todas e todos.

Mas, seriam então as teorias políticas fundadas na justiça capazes de incorporar e/ou assimilar tais transformações? Que mudanças seriam exigidas destas teorias de justiça? A resposta oferecida por Kymlicka, p. ex., conhecido estudioso do liberalismo igualitário de Rawls e Dworkin, a esta questão é bastante sintomática: segundo ele, uma leitura séria e rigorosa dos escritos feministas tem de admitir que os liberais devem renunciar ou ao compromisso com a igualdade 
sexual ou ao seu comprometimento com a separação tradicional entre o público e o privado. E justifica:

o fracasso em confrontar as desigualdades de gênero na família pode ser visto como uma traição dos princípios liberais de autonomia e igual oportunidade. De acordo com algumas críticas feministas, porém, os liberais recusam-se a interferir na família, mesmo para promover os objetivos liberais de autonomia e igual oportunidade, porque estão comprometidos com uma distinção entre público-privado, e porque vêem a família como o centro da esfera privada (KIMLICKA, 2002, p. 388).

\section{FAMÍLIA, JUSTIÇA E GÊNERO: A RESPOSTA DO} LIBERALISMO IGUALITÁRIO AO FEMINISMO E SEUS LIMITES

Uma possível resposta à pergunta sobre quais mudanças seriam necessárias nas teorias de justiça para que pudessem abarcar e assimilar as transformações apontadas como necessárias pelas críticas feministas pode ser encontrada nos trabalhos de Okin, pensadora que se propõe a entrar num debate qualificado com o pensamento liberal. A autora enxerga com clareza os problemas detectados pelas leituras feministas dos escritos liberais. No entanto, especialmente no que se refere aos acréscimos oferecidos pelo liberalismo igualitário, renovado por John Rawls no último quartel do século XX, Okin (1989, p. 108) reconhece um razoável potencial feminista tanto no método quanto nas conclusões a que chega Rawls em seu Uma Teoria da Justiça (1971) - as quais serão aperfeiçoadas mais tarde em seu Liberalismo Político (1993).

Rawls expôs, na primeira obra, suas ideias sobre a "justiça como equidade", teoria segundo a qual os princípios de justiça seriam escolhidos pelas pessoas (ou partes) a partir de condições de liberdade e igualdade. 0 autor formulou um modelo político-institucional inspirado na tradição contratualista, com base numa teoria deontológica da justiça. Lá explicou também que, para ele, os seres humanos devem ser concebidos como racionais e razoáveis, e possuidores de um senso de justiça, que é desenvolvido ao longo de toda vida no seio de uma sociedade bem-ordenada. Esta é caracterizada por Rawls como uma coletividade estruturada para promover o bem de seus membros, sendo efetivamente regulada por uma concepção comum ou senso de justiça. Desse modo, em tal sociedade, todos os indivíduos aceitam, e sabem que os outros aceitam, os mesmos princípios de justiça, sendo esse fato publicamente reconhecido. Assim, quando as instituições são justas - da forma como essa concepção define -, diz ele, os indivíduos que 
participam de tal ordenação adquirem o senso correspondente de justiça e o desejo de fazer a sua parte para mantê-las (RAWLS, 1971, p. 4-5).

Em Liberalismo Político, dos anos 1990, encontra-se também a explicitação de uma concepção importante para seu argumento, qual seja, a de que a sociedade democrática constitucional bem ordenada é caracterizada pelo fato do pluralismo razoável. Segundo Rawls, os cidadãos percebem que não podem chegar a um acordo acerca de princípios políticos de justiça com base em suas doutrinas abrangentes irreconciliáveis. Assim, dada a pluralidade de concepções de bem encontradas nas sociedades contemporâneas, sobretudo em virtude de seu pluralismo religioso e cultural, os arranjos político-institucionais dependem de um consenso abrangente sobre questões relacionadas à justiça política, o qual seja neutro em relação a visões de mundo particulares (RAWLS, 2000, p. 53-58).

Em virtude disso, precisam considerar que tipos de justificações podem oferecer razoavelmente um ao outro em matéria de questões políticas fundamentais. 0 modelo de Rawls passa então pela ideia de um equilibrio reflexivo, isto é, pela ponderação a partir de uma posição que possa ter o apoio de todos os cidadãos razoáveis. Desse modo, a proposta do autor conduz, no Liberalismo Político, à ideia do que ele chama de "consenso sobreposto" (overlapping consensus), recurso segundo o qual se abre mão de impor a toda a coletividade aquilo que é específico de uma concepção de bem. 0 consenso por sobreposição é justamente o consenso que se obtém "passando por cima" (overlapping) das características particulares de pessoas ou grupos, retendo-se somente aquilo que conforma 0 "substrato comum" às diferentes doutrinas abrangentes razoáveis. Tal substrato irá se materializar em princípios públicos/políticos de justiça que, por sua vez, deverão orientar os arranjos político-institucionais que servem de base à estrutura básica de uma determinada sociedade.

Segundo Rawls, então, os princípios de justiça são resultado do consenso estabelecido entre pessoas éticas - seres racionais com objetivos próprios (razão prática) e senso de justiça (gerado pelas instituições justas). A autonomia racional da pessoa, que tem sua base nas faculdades intelectuais e morais, permite assim a construção de uma concepção política de justiça que possa ser aceita por cidadãos livres e iguais, ainda que se diferenciem por suas doutrinas razoáveis abrangentes ${ }^{12}$

\footnotetext{
${ }^{12}$ Rawls propõe que, no raciocinar público, as doutrinas abrangentes de verdade ou direito sejam substituídas por uma ideia do politicamente razoável dirigido aos cidadãos enquanto cidadãos. Além disso, a ideia de razão pública não critica nem ataca qualquer doutrina abrangente, exceto na medida em que seja incompatível com os elementos essenciais da razão pública e de uma sociedade democrática (RAWLS, 2000, p. 53-54).
}

O GÊNERO DO PÚBLICO...

A. Silva, R. Ventura E R. Kritsch

$\bullet 73$ 
(RAWLS, 2000, p. 72). A exigência básica que se impõe aqui, no entender do autor, é que uma doutrina abrangente razoável aceite um regime democrático constitucional e a ideia de lei legítima que o acompanha. Nota-se, portanto, que Rawls compreende a concepção de justiça partilhada em comum como subjacente à ordem política: ele entende que existe uma concepção pública de justiça; e que a partir dela os indivíduos regulam suas atividades políticas e interpretam sua constituição. É exatamente isto que Rawls chama de consenso sobreposto.

De acordo com Rawls, o recurso à ideia da posição original é uma tentativa de interpretar tal noção. Segundo esse raciocínio, os princípios de justiça seriam aceitos em uma posição original de igualdade, na qual ninguém conheceria sua posição dentro da sociedade (por encontrar-se detrás de um "véu de ignorância"). Esse desinteresse derivado da ignorância da própria situação implicaria a impossibilidade de alguém razoavelmente discordar desses princípios. Desta maneira, do mesmo modo como cada um decide sobre seu bem, um grupo deveria decidir, para todos, sobre o que é justo ou injusto (RAWLS, 1971, p. 11). A posição original seria então a situação ideal para tal decisão, pois o véu de ignorância garantiria que homens racionais decidissem em situação equitativa - todos estariam em situação semelhante e ninguém poderia estipular princípios para favorecer sua condição particular. Nesta posição, supõe Rawls, as partes formulariam, no contexto de sociedades plurais bem ordenadas, dois princípios de justiça ${ }^{13}$.

$\mathrm{Na}$ tentativa de empreender uma leitura feminista da teoria da justiça política rawlsiana, Okin procura sustentar que a posição original - na qual 0 véu da ignorância ocultaria das partes seu sexo, bem como suas características particulares, talentos, circunstâncias e desejos - poderia representar um conceito

\footnotetext{
${ }^{13}$ Os dois princípios são: "1. cada pessoa deve ter um direito igual ao mais abrangente sistema total de liberdades básicas iguais que seja compatível com um sistema semelhante de liberdades para as outras. 2. As desigualdades sociais e econômicas devem ser ordenadas de tal modo que sejam ao mesmo tempo (a) consideradas como vantajosas para todos dentro dos limites do razoável, e (b) vinculadas a cargos e posições acessíveis a todos" (RAWLS, 1971, p. 60). Mais tarde, em Liberalismo político, Rawls (2000, p. 5-6) iria reformular estes princípios, de modo que 0 primeiro princípio (o de igual liberdade) estabeleça a inviolabilidade das liberdades básicas dos indivíduos numa sociedade democrática. 0 segundo princípio, por sua vez, subdividido em outros dois, seria revisto em: um que garante a igualdade de oportunidades; e outro que assegura que as desigualdades socioeconômicas só se justificam quando existem para um benefício maior do membro menos avantajado da sociedade (princípio da diferença). Rawls especifica ainda que a ordem dos princípios é léxica: o primeiro antecede o segundo, num sentido prioritário, de forma que não é permitida a violação das liberdades básicas em prol de vantagens econômicas e sociais.
} 
poderoso para a mudança na estrutura de gênero. Uma vez que as dicotomias operadas pela tradição liberal (que definem o público versus o doméstico, a esfera da vida política versus a não-política) devem ser descartadas, como já se discutiu antes, Okin acredita ser possível utilizar a teoria formulada por Rawls como parâmetro para se pensar como alcançar a justiça entre os sexos, na família e na sociedade como um todo. 0 objetivo central de sua análise é tentar entender se é possível a coexistência entre justiça e gênero.

De acordo com Okin (1989, p. 89), existem poucas indicações, em Uma Teoria da Justiça, de que as sociedades liberais contemporâneas, às quais os princípios de justiça devem ser aplicados, sejam profundamente estruturadas pelo gênero (gender-structured). Apesar disso, Okin aponta ambiguidades neste trabalho e insiste que algumas delas são "notáveis" para aquela/es que o lêem a partir de um ponto de vista feminista.

Rawls, como a maior parte dos teóricos políticos até recentemente, constata ela, emprega termos de referência masculinos genéricos. Palavras como "homem", "humanidade", "ele" são intercaladas com termos de referência de gênero neutros como "indivíduo", "pessoa moral", etc. Esse uso de linguagem poderia ser menos significante, admite Okin, se não fosse pelo fato de Rawls enquadrar-se em uma longa tradição da filosofia política e da filosofia moral que foram usadas para excluir a mulher de seu escopo de conclusão. Disso resulta a afirmação de que Rawls encontra-se em uma tradição cega ao sexismo, o que torna seus termos ainda mais ambíguos do que inicialmente poderiam parecer. A partir de tais constatações, aquela/es que procuram fazer uma leitura feminista do modelo rawlsiano, como Okin, questionam se esta teoria da justiça poderia ser ampliada para a mulher.

Para Okin (1989, p. 91), a resposta a esta questão passa pelo entendimento de que Rawls, ao desenvolver seus argumentos sobre a posição original, afirma que o sexo é uma das contingências moralmente irrelevantes que estariam escondidas pelo véu da ignorância. Porém, uma vez que no modelo rawlsiano "considera-se como um dado que elas [as partes] conhecem os fatos genéricos sobre a sociedade humana" (RAWLS, 1971, p. 138) - presumidamente incluindo o fato de que a sociedade é estruturada pelo gênero tanto em relação aos costumes quanto, em outros aspectos, pela lei -, Okin argumenta que, quer as partes saibam ou não 0 seu sexo, este poderia ser matéria suficientemente relevante para ser mencionado. Neste sentido, por um lado, afirma a autora, uma consistente e sincera aplicação 
dos princípios de justiça liberal de Rawls pode levar a desafiar o sistema de gênero que fundamenta nossa sociedade. Por outro lado, reconhece 0kin, partindo-se das formulações rawlsianas, essa proposta aparece muito mais como uma sugestão de desafio do que como uma matéria realmente desenvolvida em seus textos.

A posição original é uma ideia brilhante, reconhece ela, pois obriga que questões referentes à reconsideração de tradições, costumes, instituições, etc. sejam reformuladas a partir de diversos pontos de vista; e ainda garante que os princípios de justiça sejam aceitáveis a todos, independente da posição que "ele" ocupa ou representa. Entretanto, para muitas leitoras/es feministas, o problema da teoria reside no fato de Rawls ter encapsulado o ambíguo "ele". Sobre este ponto, Okin (1989, p. 101) argumenta que Rawls falhou em enfrentar a relação entre a justiça e o sistema de gênero - que representa uma das estruturas fundamentais das nossas sociedades e está enraizado nos papéis sexuais da família, estendendo-se os seus ramos por todos os rincões de nossas vidas. Porém, a construção do conceito de posição original, acompanhado do véu de ignorância, possibilita que uns possam colocar-se na posição ocupada pelo outro. Assim, a partir deste desenvolvimento teórico, conclui-se que é necessário mais do que uma igualdade formal entre os sexos para que a justiça seja realizada.

Okin enxerga na teoria rawlsiana um potencial para o feminismo se - e somente se - esta teoria comprometer-se com uma crítica da familia. Para ela, se a justiça como equidade deve mostrar igual respeito pelas pessoas, abolindo hierarquias de riqueza, classe e raça, então é simplesmente inconsistente e irracional não questionar a hierarquia baseada na diferença de sexo; e questionar essa hierarquia, como lembra Martha Nussbaum (2002, p. 501), exige criticar a instituição da família, pois é por meio dela que as relações hierárquicas de sexo são perpetuadas. Okin (1989, p. 108) reconhece que Rawls negligenciou questões relativas ao gênero. Lembra que 0 autor teve uma preocupação inicial com a família e sua relação com a estrutura básica da sociedade ${ }^{14}$; porém, não considerou de que forma a família poderia ser pensada como uma instituição justa.

\footnotetext{
${ }^{14}$ Em Uma Teoria da Justiça, Rawls (2000, p. 8) diz que a família monogâmica é parte da estrutura básica da sociedade e aponta três estágios para o desenvolvimento moral do indivíduo, a saber: a moralidade de autoridade, a moralidade de grupo e a moralidade de princípio. 0 primeiro deles é, em sua forma primitiva, a moralidade da criança. Rawls admite que o senso de justiça é adquirido gradualmente pelos membros mais jovens da sociedade à medida que vão crescendo; e que a sucessão de gerações e a necessidade de ensinar às crianças atitudes morais é uma das condições da vida humana.
} 
Rawls, já no início da obra, frisa Okin (idem), distingue explicitamente as instituições que compõem a estrutura básica da sociedade (que inclui a família) daquelas "associações privadas". Nos seus trabalhos posteriores, contudo, ele parece recuar e reforçar o lugar da família numa esfera "privada"; portanto, como uma associação não política, para a qual parece sugerir que os princípios de justiça são menos apropriados ou relevantes ${ }^{15}$. Em contrapartida, sua teoria do desenvolvimento moral da pessoa humana tem como ponto de partida a experiência pessoal dentro de um ambiente familiar justo e amoroso, o que consiste, para Okin, num paradoxo que, aliado à sua suposição sobre o gênero, impede Rawls de ampliar os princípios de justiça a todo o domínio do humano, leia-se, à família - reino que, na visão dela, é essencial para a conquista e manutenção da justiça.

Mas, se Rawls não abre mão do uso das dicotomias público/privado, político/não-político, e emprega termos de referência masculinos, carecendo da compreensão de que é na família que se perpetuam os problemas de gênero, como Okin sustenta então a utilidade desse modelo?

Uma resposta possível parece estar por detrás da argumentação da própria Okin, em seu debate com Rawls. 0 modelo rawlsiano, como é sabido, pretende uma neutralidade de objetivo (neutrality of aim), o que quer dizer que os princípios políticos não devem favorecer nenhum aspecto das concepções de bem que seja motivo de desacordo entre cidadãos razoáveis (RAWLS, 2000, p. 242). Ora, se a filosofia política souber captar adequadamente aquilo que é comum nessas diferentes concepções de bem, ela poderá justificar, em sociedades heterogêneas, como sugere o próprio Rawls, princípios que devam reger práticas e instituições

\footnotetext{
${ }^{15}$ As críticas feministas levaram Rawls a publicar, em The Idea of Public Reason Revisited (1997), uma resposta mais acurada a respeito da aplicação dos princípios de justiça à família. 0 problema que se põe, para Rawls, é se, numa sociedade liberal, o Estado deveria ou não constranger a família em nome da justiça. Para ele, a família deve ser vista como parte da estrutura básica da sociedade enquanto seu papel central for o de produzir e reproduzir a sociedade e sua cultura de uma geração para a outra, conduzindo de modo efetivo a criação das crianças e assegurando seu desenvolvimento moral bem como a educação inserida na cultura, de modo que os futuros cidadãos possam dispor de um senso de justiça que apóie as instituições sociais e políticas (RAWLS, 1997, p. 595-96). Todavia, ainda que Rawls continue afirmando que a família é parte da estrutura básica da sociedade e que os dois princípios da justiça se aplicam a esta estrutura, eles não se aplicariam diretamente à vida interna das famílias. Segundo ele, os princípios se aplicam à família do mesmo modo que se aplicam às instituições sociais como a igreja, o que quer dizer que, ainda que os princípios gerem leis que regulem o que as associações possam fazer, eles não dizem respeito aos seus trabalhos internos, que são deixados à escolha voluntária dos cidadãos.
}

O GÊNERO DO PÚBLICO... 
políticas, sem contudo estabelecer uma doutrina substancial ${ }^{16}$. Então, o que Okin parece tomar de Rawls é justamente a ideia de que instituições ordenadas de maneira justa poderiam fomentar entre os indivíduos um senso de justiça atento em alcançar as transformações necessárias nas estruturas da dominação de gênero.

Se os problemas identificados pelo feminismo revelam a necessidade de uma mudança na estrutura de gênero das sociedades, pode-se entender, a partir da concepção rawlsiana de filosofia política, por que Okin ainda utiliza a hipótese da posição original, apesar desta ser, em Ralws, marcada por aquela estrutura (patriarcal) que perpetua os problemas de gênero. Segundo esse raciocínio, se uma neutralidade de objetivo pode ser encontrada no consenso sobreposto, mudanças na estrutura de gênero poderiam então ser incorporadas a esse consenso e ao procedimento - que, além do mais, pode dizer-se político e não abrangente, respeitoso das diferenças.

Já que os princípios formulados na posição original são afirmados em termos de ideias fundamentais latentes na cultura política pública de uma sociedade democrática (Rawls,1971, p. 17-22), e a justificação política da neutralidade encontra-se alicerçada em elementos básicos latentes nessa cultura política pública, Okin pode pretender que mudanças estruturais resultantes de leis geradas a partir da posição original transformem também o senso de justiça, que é produzido e reproduzido, em boa medida (embora não só) no interior da família.

Okin não pode concordar com o modelo de Rawls como um todo; mas parece pensar que, a partir de propostas de transformações nas estruturas (patriarcais) de gênero, tais como encontradas nas sociedades modernas, a posição original e 0 véu de ignorância poderiam formalizar mudanças substanciais. Assim, se na posição original há um desconhecimento quanto ao sexo, as partes, ao fazerem suas escolhas, pensariam soluções para o problema da estrutura de gênero, o que acarretaria a formulação de medidas e/ou leis que combatessem tal estrutura como, por exemplo, a inclusão de textos e pensadoras/es feministas nos currículos

\footnotetext{
16 "O objetivo da filosofia política, quando ela se apresenta na cultura pública de uma sociedade democrática, é articular e tornar explícitos aqueles princípios e noções compartilhados, pensados como já latentes no senso comum; ou, como frequentemente é o caso, se o senso comum está hesitante e incerto, e não sabe o que pensar, propor a ele [ao senso comum] certos princípios e concepções conformes à natureza [congenial] de suas convicções e tradições históricas mais essenciais (RAWLS,1980, p.306)".
} 
escolares; e, com isso, alcançar-se-ia uma transformação também no senso de justiça dos cidadãos: uma modificação, portanto, simultaneamente, de forma e de conteúdo.

Se as partes na posição original não sabem seu sexo, conclui Okin, os princípios formulados designarão uma sociedade em que as diferenças de sexo não aparecerão como fundamento para a dominação. Ainda que as diferenças de sexo possam permanecer importantes nas concepções de bem dos cidadãos, elas não poderão, por meio dos princípios formulados na posição original, ter relevância política: as diferenças de sexo serão combatidas pelas leis formuladas de acordo com os princípios escolhidos pelas partes na posição original. Tudo isso quer dizer, então, que Okin enxerga em uma vertente da filosofia política cega ao sexo (blind of sex), leia-se o liberalismo igualitário, uma possível saída para a relação entre justiça e gênero?

Por maiores que possam ser os esforços de feministas como 0kin para incorporar possíveis contribuições do liberalismo voltado para a justiça e para a igualdade ao arcabouço teórico das lutas feministas pelo fim das desigualdades de gênero, não há como negar - como já se viu sobretudo nas críticas feministas às dicotomias clássicas do pensamento político de matriz ocidental, na primeira parte deste artigo - o abismo que separa um mundo "mental-epistêmico" do outro. As críticas empreendidas pela teoria feminista são profundas e, em boa medida, consequentes; e atingem o centro nervoso das teorias políticas de matriz iluminista quando põem em xeque o universo dicotômico essencialista (e patriarcalista) que as constitui.

Embora Okin procure fazer uso do instrumental rawlsiano para incrementar 0 arsenal disponível à teoria feminista, fica claro que ela toma do modelo apenas as noções básicas de "posição original" e de "véu de ignorância", rejeitando 0 restante dos pressupostos político-filosóficos já denunciados à exaustão pelo feminismo como estruturados pelo gênero (gender-structured). E, mesmo assim, toma-as apenas para fazer delas um uso instrumental na luta contra a injustiça de gênero, o que ressalta ainda mais a fragilidade do liberalismo igualitário e sua incapacidade de solucionar o problema da justiça no interior da família, dada sua obsessão pelas dicotomias (patriarcais) público-privado e público-doméstico, que terminam por isentar as relações internas à família do crivo da justiça pública. 
Diante de uma tal fragilidade, até mesmo pensadores assumidamente liberais, como p. ex. Kymlicka, convenceram-se da justeza da reivindicação das feministas em relação à dicotomia público/privado e defendem uma revisão coerente da posição liberal em vários aspectos relacionados ao problema de gênero. Para este autor, não só teorias da justiça devem dar mais atenção aos efeitos da organização familiar para a vida das mulheres como ainda "a intimidade precisa de defesa fora da família tradicional, e a solidão precisa ser defendida dentro da família". Segundo ele,

A linha entre privacidade e não-privado [...] vai além da distinção tradicional público/doméstico. Embora tenhamos esperança de que a família forme um 'domínio de privacidade e retiro pessoal', para muitas pessoas a família é, ela própria, uma instituição da qual desejam privacidade, e a ação estatal pode ser necessária dentro da esfera doméstica para proteger a privacidade e impedir 0 abuso. E nem a distinção liberal Estado-sociedade nem 0 direito liberal à privacidade previnem tal ação. [E adiante:] A família não tem sido tanto relegada ao domínio privado quanto simplesmente ignorada por inteiro. E os interesses das mulheres são prejudicados pela omissão da teoria política em examinar a família tanto nos seus componentes políticos quanto privados. Pois os papéis de gênero associados à família tradicional estão em conflito não apenas com os ideais públicos de direitos e recursos iguais, mas também com a compreensão liberal das condições e valores da vida privada (KIMLICKA, 2002, p. 398).

Várias questões, no entanto, permanecem em aberto tanto para 0 liberalismo quanto para o feminismo: deve a justiça pública do Estado alcançar, inclusive, as relações de amor e amizade em nome da justiça individual e da igualdade entre os sexos? A família (ou mesmo o 'casal') deve ser compreendida como uma esfera à salvaguarda da interferência do Estado? E ainda, seria possível formular respostas plausíveis a tais questionamentos que não operassem com as dicotomias utilizadas até aqui, público versus privado, esfera política versus nãopolítica? Tudo indica que o feminismo, mas muito mais ainda o liberalismo, têm muito com que se debater. 


\section{REFERÊNCIAS}

ALLEN, Anita L. Uneasy access: privacy for women in a free society. LanhamOxford: Rowman and Littlefield Publishers, 1988.

ARENDT, Hannah. A condição bumana. Rio de Janeiro: Forense Universitária, 1981.

BENHABIB, Seyla. El ser y el outro en la ética contemporânea: feminismo, comunitarismo y posmodernismo. Barcelona: Ed. Gedisa, 2006.

BEAUVOIR, Simone. O segundo sexo. Rio de Janeiro: Nova Fronteira, 1980.

CONSTANT, Benjamin. Da liberdade dos antigos, comparada à dos modernos. Tradução de Loura Silveira. Revista de Filosofia Política, São Paulo, n. 2, 1985.

FIRESTONE, Shulamith. The dialectic of sex. London: The Women's Press, 1970.

GILLIGAN, Carol. In a differente voice: psychological theory and womes's development. Cambridge: Harvard University Press, 1982.

GROSS, Elisabeth. What is feminist theory? In: PATEMAN, Carole. \& GROSS, Elisabeth (orgs.), Feminist challenges: social and political theory. Boston: Northeastern Press, 1987, (C)1986.

JAGGAR, Alison M. Feminist politics and human nature. Lanham-0xford: Rowman \& Littlefield Publishers, 1983.

KIMLYCKA, Will. Contemporary political philosophy. Oxford: Oxford University Press, 2002.

MACKINNON, Catharine. A. Feminism unmodified: discourses on life and law. Cambridge-Massachusetts: Harvard University Press, 1987.

MENDUS, Susan e KENNEDY, Ellen. Women in western political philosophy: Kant to Nietzsche. Brighton: Wheatshef Books, 1987.

MILLET, Kate. Sexual politics. London: Virago, 1969.

NUSSBAUM, Martha. Rawls and feminism. In: FREEMAN, Samuel. (Ed.) The Cambridge Companion to Rawls. Cambridge: Cambridge University Press, 2003. OAKLEY, Ann. Sex, gender and society. London: Temple Smith, 1985 [1972]. OKIN, Susan Moller. Women in western political thought. London: Virago, 1979. . Justice and gender. Philosophy and public affairs, Oxford, vol. 16, n. 1, 1987 
.Justice, gender and the family. New York: Basic Books, 1989.

. The public/private dichotomy. In: FARRELLY, Colin (org.) Contemporary political theory. London: Sage, 2004.

. Gênero, o público e o privado. Estudos feministas, Florianópolis, vol.16, n. 2, 2008 .

PATEMAN, Carole. The disorder of women. Cambridge-Oxford: Polity Press-Basil Blackwell, 1989.

. O contrato sexual. São Paulo: Paz e Terra, 1993.

RAWLS, John. A theory of justice. Oxford: Oxford University Press, 1971.

. Kantian constructivism in moral theory. In: Collected Papers, Cambridge: Harvard University Press, 1999 [1980]. . Liberalismo político. São Paulo: Ática, 2000.

. Resposta a Habermas. Educação e Sociedade, Campinas, vol. 17, n. 57, 1996.

The Idea of Public Reason Revisited. [1997] In: Collected Papers, Cambridge: Harvard University Press, 1999.

ROSENBLUM, Nancy. Another liberalism. Romanticism and the reconstruction of liberal thought. Cambridge-Massachusetts: Harvard University Press, 1987.

RUDDICK, Sara. Maternal thinking: towards a politics of peace. Boston: Beacon Press, 1995.

YOUNG, Iris Marion. Polity and group difference: a critique of the ideal of universal citizenship. Ethics, Chicago, vol. 99, n. 2, 1989.

WEINSTEIN, Wendy L. The private and the free: a conceptual inquiry. In: PENNOCK, J. Roland \& CHAPMAN, John W. (orgs.). Privacy: Nomos XIII. New York: Atherton, 1971. 